\title{
Overcoming the Technical Challenges of Total Knee Arthroplasty in Patients Affected by Hereditary Multiple Exostoses: Our Experience Managing the Bone Deformities
}

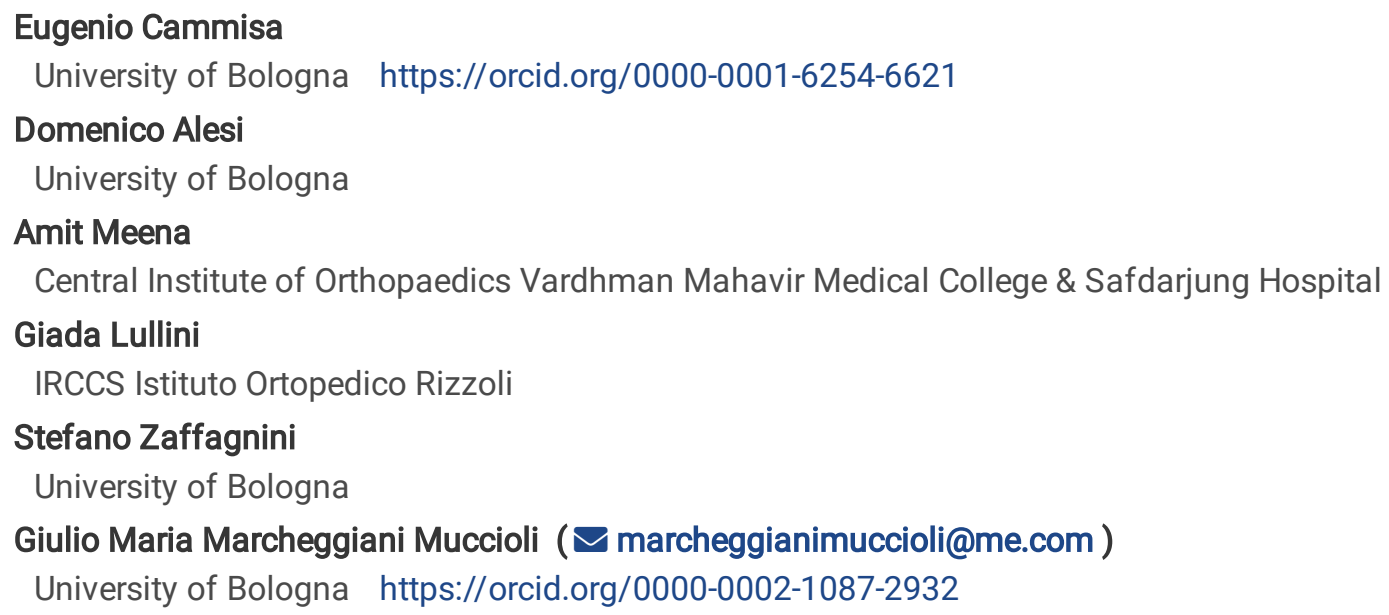

\section{Case report}

Keywords: Hereditary multiple exostoses, Total knee arthroplasty

Posted Date: May 27th, 2021

DOI: https://doi.org/10.21203/rs.3.rs-542388/v1

License: (1) This work is licensed under a Creative Commons Attribution 4.0 International License. Read Full License 


\section{Abstract}

Introduction: Hereditary multiple exostoses (MHE), also known as familiar osteochondromatosis or diaphyseal aclasis, is an autosomal dominant inherited genetic pathology that is characterized by the presence of multiple benign osteochondromas (exostoses). Knee deformity is common in patients with $\mathrm{HME}$, with nearly a third of patients developing genu valgus. Total knee arthroplasty (TKA) has been used to correct valgus deformities with advanced knee osteoarthritis (OA). However concomitant limb deformities and altered anatomy of the knee make this surgery particularly challenging.

Case presentation: We present the case of a 50 years old Caucasian woman, affected by multiple hereditary exostoses, who came to our attention for progressive pain in the right knee. Upon further examination the knee had a prominent valgus alignment, concomitant valgus instability and flexion contraction. The patient was treated with one stage total knee arthroplasty using a semiconstrained design. The patient was re-evaluated at 24 months follow-up and there were no signs of implant loosening, the knee function improved significantly and the patient was very satisfied

Conclusions: We also present a mini-review of the literature on this topic. Given the recurring technical difficulties of such procedure in these patients, we describe our experience as well as the need for preoperative planning, the use of appropriate constrain when required, the high frequency of ligament instability, bony defects, and patellar maltracking. TKA must be considered when necessary, in these patients, as good to excellent clinical results can be achieved and maintained, allowing for significant improvements in quality of life.

\section{Introduction}

Hereditary multiple exostoses (HME), also known as familiar osteochondromatosis or diaphyseal aclasis, is an autosomal dominant inherited genetic pathology that is characterized by the presence of multiple benign osteochondromas (exostoses). Osteochondroma is a cartilage-capped bony outgrowth, which is broad-based (sessile) or stemmed (pedunculated) and is composed of cortex and a marrow cavity both continuous with the host bone. It is a rare condition that affects roughly 1 in 50,000 people[1, 2].

The most common location for osteochondromas is the lateral side of the most active growth plate of a long bone. In more than $80 \%$ of cases, it is diagnosed before the end of the first decade of life [2].

Depending on their size, location, and number the osteochondromas can cause compression of tendons, muscles, nerves, and blood vessels, all of which may lead to pain and motion impairment. HME may also cause skeletal deformities and growth restriction by interfering with normal growth plate function. It may also result in bowing and shortening of the forearms, short stature, limb-length discrepancy, restricted range of motion, angular deformity of the knee, and flat foot [3]

Knee deformity is common in patients with $\mathrm{HME}$, with nearly a third of patients developing genu valgus [4]. The most common site is the proximal tibial metaphysis, but it may also be present at the femur. The presence of osteochondromas at the knee may lead to an oblique joint line orientation that may be responsible for the development of arthritis at a relatively younger age. Moreover, this increased angulation might lead to lateral patella subluxation and patellofemoral complaints. Due to all these clinical symptoms patients with HME have lower reported sports activities and the need for earlier intervention compared to the average population [5].

Options for surgical management of HME affecting the knee may include exostoses resection, joint deformity correction, and correction of limb-length discrepancy [6]. Opening wedge osteotomy and blade plate fixation of the distal femur have been used to correct valgus knee with a predominant femoral component, whereas if the deformity is mainly at the tibial side then high tibial osteotomy can be performed [7]. In young patients, hemiepiphysiodesis can be a viable option to correct knee deformities in the developmental phase. On rare occasions, total knee arthroplasty (TKA) was used to correct valgus deformities with advanced knee osteoarthritis (OA) [6].

To the current authors' knowledge, very few reports are available in the literature on TKA in HME patients. In this paper, a review of the literature on this topic is presented. Given the recurring technical difficulties of such procedure in these patients, we report a case of a young woman treated with TKA for early OA in HME.

Page $2 / 12$ 


\section{Case Presentation \\ Preoperative evaluation}

We present the case of a 50 years old Caucasian woman, affected by multiple hereditary exostoses, who came to our attention for progressive pain in the right knee. The patient had already undergone several surgeries to resect the more prominent

osteochondromas around the knee that were causing nerve compression and disability. At the physical evaluation, the patient was able to walk unassisted only for short distances without a cane, although with a prominent limp. The right limb had a prominent valgus alignment (Fig. 1,2). The palpation of the knee elicited pain in the lateral compartment, which was also the most painful side during walking. The range of motion of the knee was highly restricted, it presented a flexion contracture of $20^{\circ}$ and a range of motion (ROM) of $20-90^{\circ}$ in the sagittal plane, anterior knee pain was reported, and the knee was unstable at valgus stress as for medial collateral ligament (MCL) insufficiency. There was no sign of neurovascular disorders. Preoperative Knee Society Score (KSS) Knee Score was 30, Function Score was 35. Knee Injury and Osteoarthritis Outcome Score (KOOS) was 26.8.

A preoperative evaluation was done on long leg standing radiograph and lateral radiograph of the affected knee. Given the pronounced metaphyseal deformity, a computed tomography (CT) of the knee with 3D reconstructions was also acquired. The exams showed a valgus alignment with a medial deviation of the knee from the mechanical axis, moderate OA (Kellegren Lawrence grade II) of the knee was also present. The hip-knee-ankle angle (HKA) was $167^{\circ}$, the tibial metaphysis was deformed in valgus. Proximal tibiofibular adhesion, talus valgus angulation greater than $20^{\circ}$ and flat foot were also present. No limb length discrepancy was found (Fig. 1)

No bone scan was performed due to the low risk of malignant transformation of the osteochondromas, especially in adults. Moreover, histological examinations showed no signs of malignancies on the previously resected lesions, and a comparison with older radiographs showed no lesions progression.

The case was thoroughly discussed with the patient and given the laxity of the knee, the flexion contracture, and the poor ROM, a TKA was considered to be the most adequate treatment.

The patient was informed that data from the case would be submitted for publication, and gave their consent.

\section{Surgical technique}

The senior author performed the surgery. The patient was positioned in a supine position. A tourniquet was used and a midline skin incision was done. A medial parapatellar approach was made to expose the joint. Care was used when performing medial dissection to not further damage the MCL. The implant chosen was a constrained condylar knee (Legion Revision Knee System, Smith\&Nephew, Andover, MA, USA).

Tibial cut first technique was used; the correct positioning of the intramedullary reamers was assessed with fluoroscopy using progressively larger diameter reamers. The tibial alignment guide was then positioned and the appropriate resection was performed. The femur followed in a similar fashion. The components chosen were a tibial component size 2 with a $14 \times 160 \mathrm{~mm}$ stem and a $6 \mathrm{~mm}$ offset, femoral component size 4 with a stem 14x220 mm and a $2 \mathrm{~mm}$ offset with an articular insert size $9 \mathrm{~mm}$. The articular surface of the patella was resected and a patellar component of $29 \mathrm{~mm}$ was implanted. To establish the rotation of the femoral component the trans-epicondylar axis was used, for the tibial component rotation the tibial crest, anterior tibial tuberosity, and the I inter-metatarsal space were used as landmarks. Tourniquet was temporarily removed before the cementation of the components in order to perform accurate haemostasis, and then repositioned. Only the tibial baseplate, the femoral component, and the patella were cemented, leaving the porous titanium surface of the stems in full contact with the bone. Given the hollow femoral metaphysis, additional cement was used to fill the space. Slight iliotibial band release was performed in order to obtain a symmetric extension gap and within $2 \mathrm{~mm}$ from the flexion gap. Patellar tracking was optimized with a lateral release. No instability in extension, mid-flexion, and flexion was encountered. Intraoperative ROM was $0-100^{\circ}$. One intraarticular drain was positioned before closure.

\section{Postoperative care and evaluation}


The day after surgery walking was allowed with full weight-bearing as tolerated and with the aid of two crutches. Continuous passive motion (CPM) was prescribed 2 times a day for 30 min.

The first follow-up visit was at 30 days after surgery. New anteroposterior long leg standing radiographs were acquired, showing good implant positioning and neutral alignment of the knee (Fig. 3, 4). Walking without crutches was encouraged. The knee ROM was 0-90 and it was stable in AP and varus-valgus throughout the entire range of flexion. Slight knee pain was reported (VAS 4) which subsided in the following weeks. Foot orthoses were prescribed, to support the medial longitudinal arc and to compensate the valgus hindfoot.

The final evaluation was at 2 years after surgery. KSS knee score was 80 and the functional score was 90 . KOOS was 87 . The knee ROM in flexion-extension was 0-100 and there was no knee instability on all planes. The patient was satisfied with the surgical outcome and was able to return to perform all the activities of daily living.

\section{Discussion}

HME most commonly affects the long and flat bones, and it may lead to severe limb deformities. Several surgical options must be carefully considered, and it is important to choose the right treatment for each patient. HME patient can present a plethora of joint conditions which can have a wide range of morbidities: purely aesthetic deformities, bony prominences causing soft tissue compressions, limb malalignment, ligament instability, OA. All painful lesions must be pre-emptively studied for any sign of malignancy. Although in adults the malignant transformation rate is pretty low (1 to 5\%)[8], bone scans can be utilized when there is a suspect of growth.

The case report we presented shows the treatment of a rare condition that may lead to the need of knee joint replacement at a young age. When possible, in patients affected by HME, other less invasive surgical treatments should be considered before proposing a total knee replacement, such as osteotomies around the knee, resection of the osteochondromas, nerve and blood vessel decompression, and soft tissue releases. However, in the presence of end-stage knee osteoarthritis, whether primary or secondary to the underlying condition, TKA should be considered to improve function and quality of life. Moreover, given the bone deformities and relative worse bone quality, other joint preserving surgeries often do not guarantee satisfactory results.

As a general rule, when choosing TKA constraint, ligament instability and bone stock should be evaluated pre-operatively with purpose of choosing an appropriate implant with the least possible degree of constraint that guarantees good stability $[9,10]$. The ligament balance is often troublesome in HME affected knees $[6,11]$. In the presented case there was no significant bone loss but a remarkable insufficiency of the MCL. The choice of a constrained condylar knee (CCK) type of implant allowed us to achieve good knee stability without relying solely on the patient's ligaments. Moreover, this type of implant, if needed, allows future revision with a hinged system, which has to be considered given the patient's young age.

As proposed by Morgan-Jones et al. [12] when using a knee revision implant, fixation in at least two zones out of three (the epiphysis, the metaphysis and the diaphysis) should be achieved. In patients with HME, the presence of bone deformities and joint degeneration often poses a challenge in this regard. In our case, it was possible to achieve good epiphyseal fixation thanks to the relatively small bone loss. Diaphyseal fixation was obtained with the use of properly sized stems, with hybrid cementation. Cement was also used to fill the metaphysis allowing for additional stability of the implant.

Lateral soft-tissue release was performed, but there was no need for sliding lateral epicondyle osteotomy to balance the prosthesis. In cases of more severe ligament damage, a hinged type of implant should be considered: in our case it was readily available but was not needed in the end.

For cases with combined OA and extraarticular deformities, Grzelecki et al [13] proposed one stage TKA and tibial shaft osteotomy, with good results. They proposed the use of a stemmed prosthesis which provided the necessary fixation at the osteotomy site without the need for additional means of osteosynthesis. The use of a hybrid cementation technique on the tibial stem must be noted, to allow proper bone healing at the osteotomy site.

Fernandez-Perez et al.[14] reported a similar case of severe OA in a valgus knee in a patient affected by HME. The authors used a different approach than ours. They propose the use of metaphyseal sleeves to reduce the need for long stems, thus avoiding 
extraarticular deformities. It must be noted that this is not always possible, as most osteochondromas affect the metaphyseal part of the bone, close to the joint. We believe the choice of long stems, with an appropriate off-set, provides better fixation and stability to the implant. The positioning of the offsets, when possible, should be planned with the aid of computed tomography (CT) images.

The choice of the component and stem size is in our experience of utmost importance. The joints affected by osteochondromas are usually abnormally enlarged, requiring careful sizing of the components. Proper stem contact with the cortical bone must be achieved for optimal stability. It is not rare to use components and stems significantly bigger than what a patient with a similar height would require, as also stated by Mesfin et al [6].

Similar challenges were reported by Kim et al [11] in their case series, where 5 patients with HME underwent TKA. The authors underline the importance of preoperative planning, the use of appropriate constrain when required, the high frequency of ligament instability, bony defects, and patellar maltracking.

The results obtained by the aforementioned authors are summarized in Table 1. 
Table 1

\begin{tabular}{|c|c|c|c|c|c|c|c|c|c|c|c|}
\hline Author & Gender & Age & $\begin{array}{l}\text { Preop } \\
\text { knee } \\
\text { alignment }\end{array}$ & $\begin{array}{l}\text { Implant } \\
\text { used }\end{array}$ & PROMs & Pre & Post & $\mathrm{FU}$ & $\begin{array}{l}\text { ROM } \\
\text { pre }\end{array}$ & $\begin{array}{l}\text { ROM } \\
\text { post }\end{array}$ & Comments \\
\hline \multirow{2}{*}{$\begin{array}{l}\text { Grzelecki } \\
\text { et al.[6] }\end{array}$} & \multirow[t]{2}{*}{$M$} & \multirow[t]{2}{*}{65} & \multirow{2}{*}{$\begin{array}{l}15^{\circ} \\
\text { valgus }\end{array}$} & \multirow[t]{2}{*}{ CCK } & KSS & 2 & 80 & \multirow{2}{*}{$\begin{array}{l}1 \\
Y\end{array}$} & \multirow{2}{*}{$\begin{array}{l}30- \\
110^{\circ}\end{array}$} & \multirow{2}{*}{$\begin{array}{l}0- \\
110^{\circ}\end{array}$} & \multirow{2}{*}{$\begin{array}{l}\text { Tibial } \\
\text { osteotomy }\end{array}$} \\
\hline & & & & & $\begin{array}{l}\text { Functional } \\
\text { Score }\end{array}$ & 40 & 75 & & & & \\
\hline \multirow{3}{*}{$\begin{array}{l}\text { Fernandez- } \\
\text { Perez et al. } \\
\text { [5] }\end{array}$} & \multirow[t]{3}{*}{$M$} & \multirow[t]{3}{*}{67} & \multirow{3}{*}{$\begin{array}{l}45^{\circ} \\
\text { valgus }\end{array}$} & \multirow{3}{*}{$\begin{array}{l}\text { CCK with } \\
\text { metaphyseal } \\
\text { sleeve }\end{array}$} & KSS & 14 & 82 & \multirow{3}{*}{$\begin{array}{l}6 \\
M\end{array}$} & \multirow{3}{*}{$\begin{array}{l}0- \\
120^{\circ}\end{array}$} & \multirow{3}{*}{$\begin{array}{l}10- \\
105^{\circ}\end{array}$} & \multirow{3}{*}{$\begin{array}{l}\text { Popliteal } \\
\text { tendon } \\
\text { release }\end{array}$} \\
\hline & & & & & $\begin{array}{l}\text { Functional } \\
\text { Score }\end{array}$ & 55 & 65 & & & & \\
\hline & & & & & WOMAC & 61.4 & 90.2 & & & & \\
\hline \multirow{11}{*}{$\begin{array}{l}\text { Kim et al. } \\
\text { [7] }\end{array}$} & \multirow[t]{2}{*}{$\mathrm{F}$} & \multirow[t]{2}{*}{80} & \multirow{2}{*}{$\begin{array}{l}11^{\circ} \\
\text { valgus }\end{array}$} & \multirow[t]{2}{*}{ PS } & KSS & 60 & 90 & \multirow{2}{*}{$\begin{array}{l}3.5 \\
Y\end{array}$} & \multirow{2}{*}{$\begin{array}{l}5- \\
118^{\circ}\end{array}$} & \multirow{2}{*}{$\begin{array}{l}0- \\
100^{\circ}\end{array}$} & \multirow{2}{*}{$\begin{array}{l}\text { Lateral } \\
\text { retinacular } \\
\text { release }\end{array}$} \\
\hline & & & & & $\begin{array}{l}\text { Functional } \\
\text { Score }\end{array}$ & 60 & 100 & & & & \\
\hline & \multirow[t]{4}{*}{$M$} & \multirow[t]{2}{*}{71} & \multirow{2}{*}{$\begin{array}{l}45^{\circ} \\
\text { valgus }\end{array}$} & \multirow[t]{2}{*}{$\mathrm{CCK}$} & KSS & 40 & 89 & \multirow{2}{*}{$\begin{array}{l}4 \\
Y\end{array}$} & \multirow{2}{*}{$\begin{array}{l}0- \\
100^{\circ}\end{array}$} & \multirow{2}{*}{$\begin{array}{l}0- \\
110^{\circ}\end{array}$} & Lateral \\
\hline & & & & & $\begin{array}{l}\text { Functional } \\
\text { Score }\end{array}$ & 50 & 100 & & & & $\begin{array}{l}\text { retinacular } \\
\text { release; } \\
\text { quadriceps } \\
\text { snip; } \\
\text { peronael } \\
\text { nerve palsy }\end{array}$ \\
\hline & & 72 & $45^{\circ}$ & CCK & KSS & 40 & 87 & 3 & $0-$ & $0-$ & Lateral \\
\hline & & & & & $\begin{array}{l}\text { Functional } \\
\text { Score }\end{array}$ & 50 & 100 & & & & osteotomy \\
\hline & $M$ & 60 & $\begin{array}{l}15^{\circ} \\
\text { valgus }\end{array}$ & CCK & KSS & 49 & 90 & $\begin{array}{l}5 \\
Y\end{array}$ & $\begin{array}{l}0- \\
120^{\circ}\end{array}$ & $\begin{array}{l}0- \\
100^{\circ}\end{array}$ & $\begin{array}{l}\text { Lateral } \\
\text { retinacular }\end{array}$ \\
\hline & & & & & $\begin{array}{l}\text { Functional } \\
\text { Score }\end{array}$ & 45 & 80 & & & & $\begin{array}{l}\text { release; } \\
\text { quadricep } \\
\text { snip }\end{array}$ \\
\hline & & 65 & $45^{\circ}$ & CCK & KSS & 49 & 90 & 10 & $0-$ & $0-$ & Lateral \\
\hline & & & & & $\begin{array}{l}\text { Functional } \\
\text { Score }\end{array}$ & 45 & 80 & & & & $\begin{array}{l}\text { realignment; } \\
\text { lateral }\end{array}$ \\
\hline & & & & & & & & & & & $\begin{array}{l}\text { epicondylar } \\
\text { osteotomy; } \\
\text { peroneal } \\
\text { nerve palsy }\end{array}$ \\
\hline $\begin{array}{l}\text { Mesfin et } \\
\text { al.[8] }\end{array}$ & $M$ & 52 & NA & PS & NA & & & $\begin{array}{l}6 \\
W\end{array}$ & $\begin{array}{l}15- \\
95^{\circ}\end{array}$ & $\begin{array}{l}5- \\
95^{\circ}\end{array}$ & $\begin{array}{l}\text { lleotibial } \\
\text { band } \\
\text { piecrust, } \\
\text { popliteal } \\
\text { tendon } \\
\text { release }\end{array}$ \\
\hline $\begin{array}{l}\text { CCK: Constra } \\
\text { Score. }\end{array}$ & ed Con & $\mathrm{Kn}$ & PS: Post & Stabilized; & Is: Patie & & & & ur & s: 1 & Society \\
\hline
\end{tabular}

\section{Conclusions}

The current literature on TKA in patients with multiple hereditary exostoses is scarce. These patients present altered anatomy and secondary joint pathologies that make this procedure technically challenging. Nonetheless, TKA must be considered when 
necessary, as good to excellent clinical results can be achieved and maintained, allowing for significant improvements in quality of life.

\section{Abbreviations}

HME: Hereditary multiple exostoses; TKA: Total Knee Arthroplasty; OA: Osteoarthritis; ROM: Range Of Motion; MCL: Medial Collateral Ligament; KSS: Knee Society Score; KOOS: Knee Injury and Osteoarthritis Outcome Score; CPM: Continuous Passive Motion; VAS: Visual Analog Scale; CCK: constrained condylar knee CT: Computed Tomography

\section{Declarations}

\section{Acknowledgements}

Not applicable.

\section{Authors' contributions}

EC, GMMM designed the research, developed the concept of the article, acquired the data and revised it critically for important intellectual content. EC analyzed the data. GM, SZ, GL contributed to interpretation of data. EC, DA, AM drafted the manuscript. All authors read and approved the final manuscript.

\section{Funding}

This research did not receive any specific grant from funding agencies in the public, commercial, or not-for-profit sectors.

\section{Availability of data and materials}

Not applicable to this article, no datasets were analyzed.

\section{Ethics approval and consent to participate}

The study was performed in accordance with the Declaration of Helsinki.

\section{Consent for publication}

Written informed consent was obtained from the patient for the scientific and educational use during the admission to the hospital in relation to hospital and national regulations including GDPR. Additionally, verbal consent and $x$-rays were obtained from the patient for the use in this publication, excluding personal data information and image.

\section{Competing interests}

The authors declare that they have no competing interests.

\section{References}

1. Porter DE, Lonie L, Fraser M, Dobson-Stone C, Porter JR, Monaco AP. et al. Severity of disease and risk of malignant change in hereditary multiple exostoses: A GENOTYPE-PHENOTYPE STUDY. The Journal of Bone Joint Surgery British volume. 2004;86B:1041-6.

2. Schmale GA, Conrad EU, Raskind WH. The natural history of hereditary multiple exostoses. The Journal of Bone Joint Surgery. 1994;76:986-92.

3. D'Ambrosi R, Barbato A, Caldarini C, Biancardi E, Facchini RM. Gradual ulnar lengthening in children with multiple exostoses and radial head dislocation: results at skeletal maturity. J Child Orthop. 2016;10:127-33.

4. Clement ND, Porter DE. Can deformity of the knee and longitudinal growth of the leg be predicted in patients with hereditary multiple exostoses? A cross-sectional study. Knee. 2014;21:299-303. 
5. D'Ambrosi R, Caldarini C, Ragone V, Facchini RM. Effect of multiple hereditary exostoses on sports activity in children. J Orthop. 2018;15:927-30.

6. Mesfin A, Goddard MS, Tuakli-Wosornu YA, Khanuja HS. Total Hip and Knee Arthroplasty in Patients With Hereditary Multiple Exostoses. Orthopedics. 2012;35:e1807-10.

7. Pierz KA, Stieber JR, Kusumi K, Dormans JP. Hereditary Multiple Exostoses: One Center's Experience and Review of Etiology: Clinical Orthopaedics and Related Research. 2002;401:49-59.

8. Bovée JV. Multiple osteochondromas. Orphanet J Rare Dis. 2008;3:3.

9. Vasso M, Beaufils P, Schiavone Panni A. Constraint choice in revision knee arthroplasty. Int Orthop. 2013;37:1279-84.

10. Alesi D, Meena A, Fratini S, Rinaldi VG, Cammisa E, Lullini G. et al. Total knee arthroplasty in valgus knee deformity: is it still a challenge in 2021? Musculoskelet Surg. 2021. 10.1007/s12306-021-00695-x.. . doi.

11. Kim RH, Scuderi GR, Dennis DA, Nakano SW. Technical Challenges of Total Knee Arthroplasty in Skeletal Dysplasia. Clin Orthop Relat Res. 2011;469:69-75.

12. Morgan-Jones R, Oussedik SIS, Graichen H, Haddad FS. Zonal fixation in revision total knee arthroplasty. The Bone Joint Journal. 2015;97-B:147-9.

13. Grzelecki D, Szneider J, Marczak D, Kowalczewski J. Total knee arthroplasty with simultaneous tibial shaft osteotomy in patient with multiple hereditary osteochondromas and multiaxial limb deformity - a case report. BMC Musculoskelet Disord. 2020;21:233.

14. Fernandez-Perez SA, Rodriguez JA, Beaton-Comulada D, Colon-Miranda RG, Soler-Salas AH, Otero-Lopez A. Total knee arthroplasty in patients with multiple hereditary exostoses. Arthroplasty Today. 2018;4:325-9.

\section{Figures}




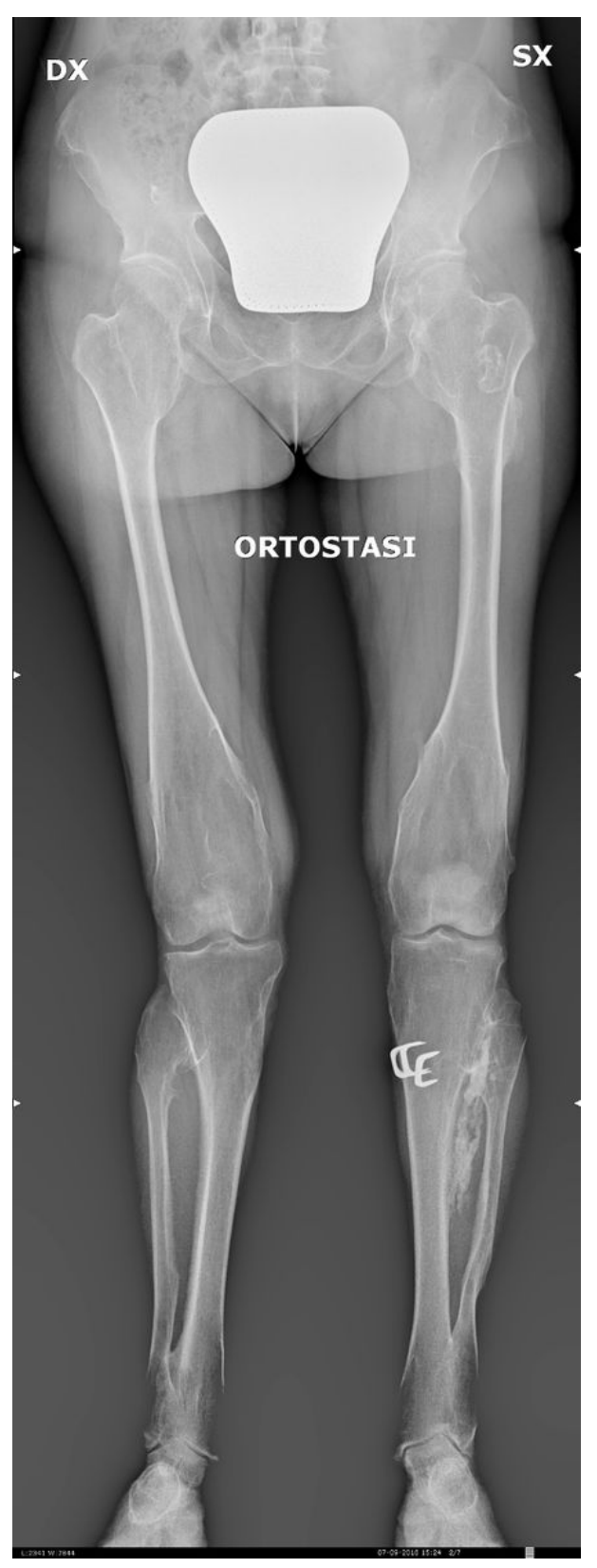

Figure 1

Radiographs showing leg alignment before surgery 


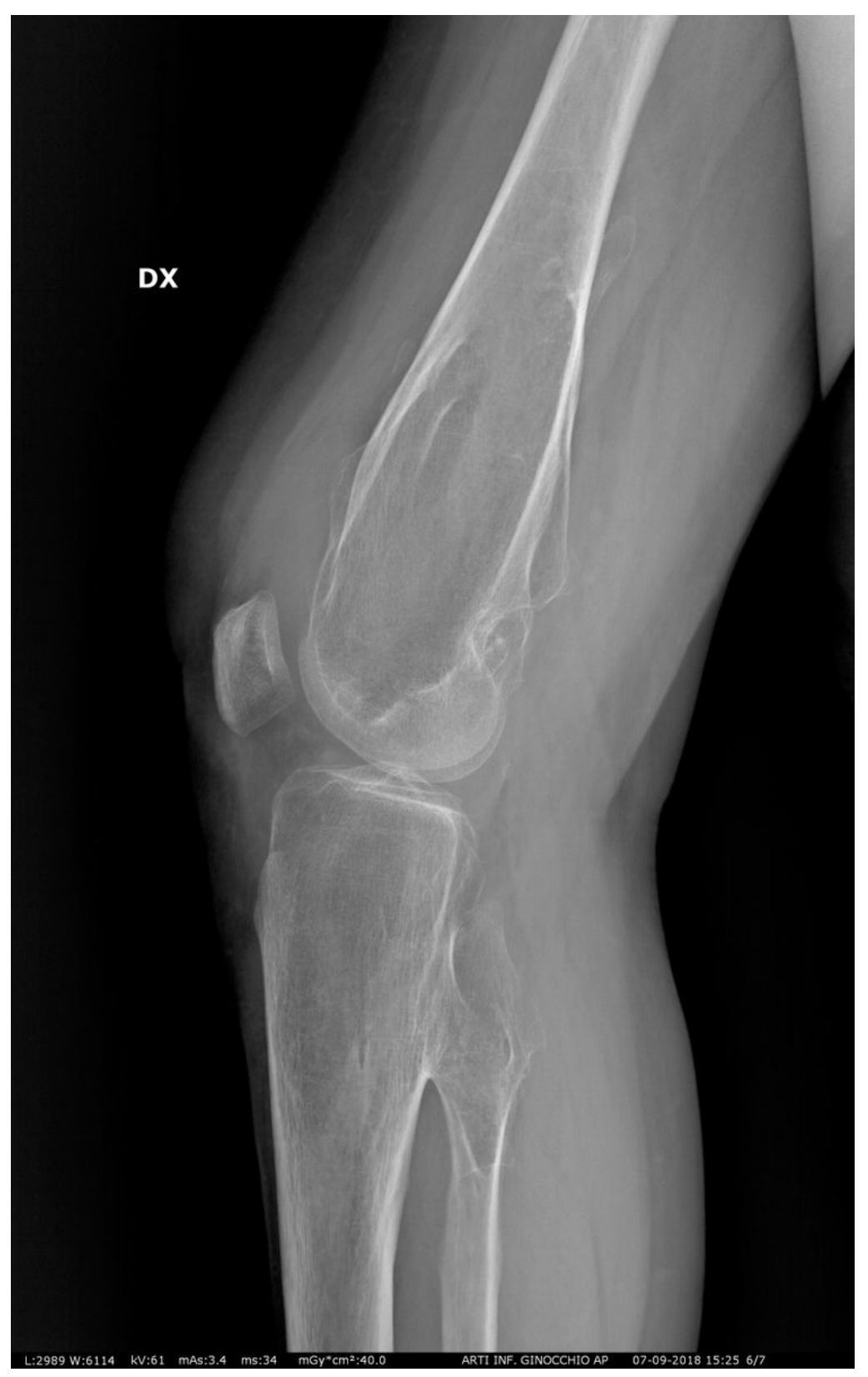

\section{Figure 2}

Radiographs showing leg alignment before surgery 


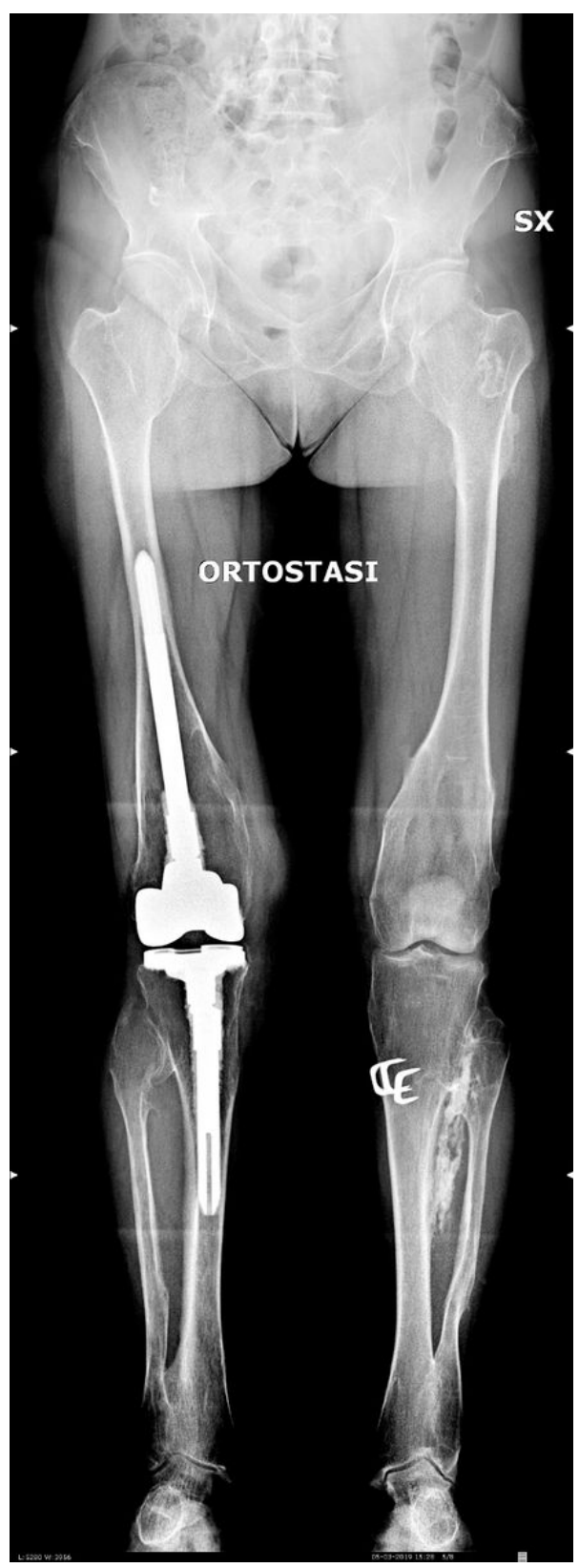

Figure 3

Radiographs at 2 years of follow-up after TKA 


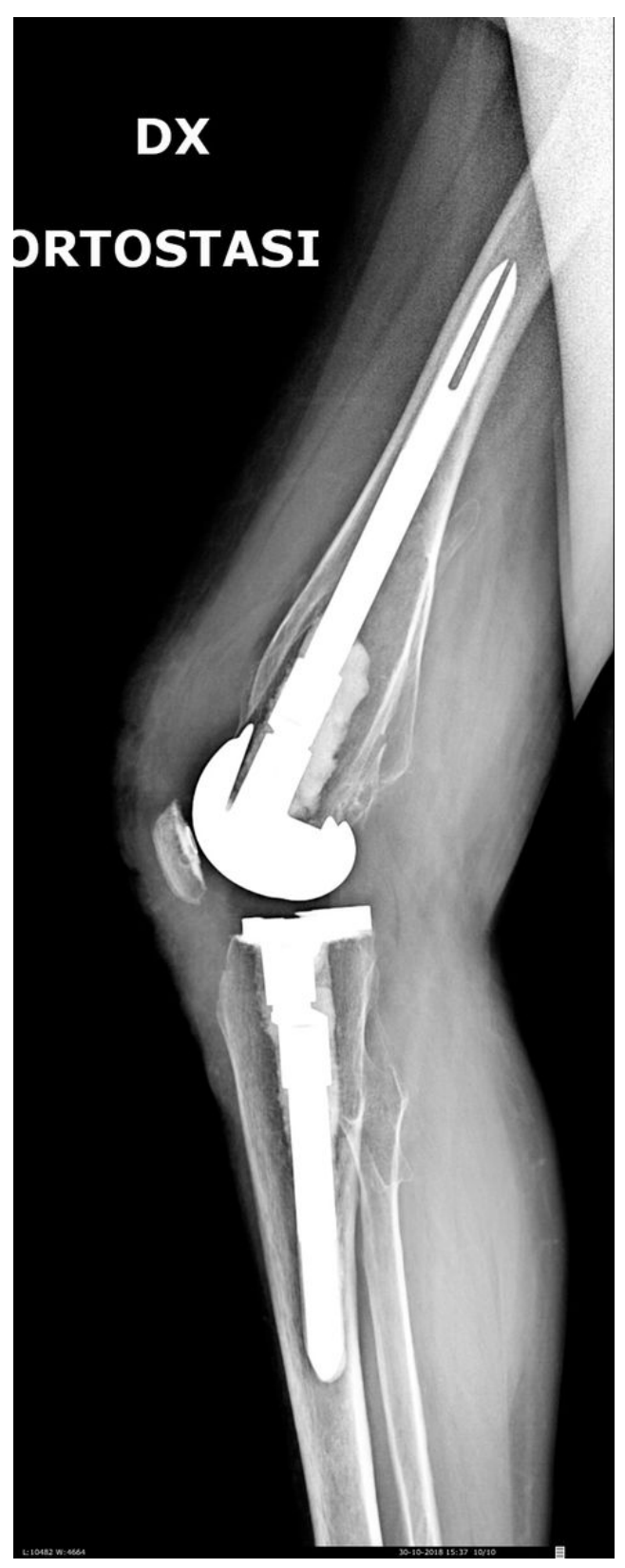

Figure 4

Radiographs at 2 years of follow-up after TKA

\section{Supplementary Files}

This is a list of supplementary files associated with this preprint. Click to download.

- CARE.pdf

- CORETIPS.docX 